\title{
Gradhiva
}

GRADHIV

Revue d'anthropologie et d'histoire des arts

$4 \mid 2006$

Le commerce des cultures

\section{La danse des grands masques amazoniens}

Chronique d'un événement

Franck Beuvier

\section{CpenEdition}

Journals

Édition électronique

URL : http://journals.openedition.org/gradhiva/609

DOI : $10.4000 /$ gradhiva.609

ISSN : 1760-849X

Éditeur

Musée du quai Branly Jacques Chirac

Édition imprimée

Date de publication : 1 novembre 2006

Pagination : 115-122

ISBN : 2-915133-44-1

ISSN : 0764-8928

Référence électronique

Franck Beuvier, "La danse des grands masques amazoniens », Gradhiva [En ligne], 4 | 2006, mis en ligne le 15 novembre 2009, consulté le 01 mai 2019. URL : http://journals.openedition.org/ gradhiva/609; DOI : 10.4000/gradhiva.609

Ce document a été généré automatiquement le 1 mai 2019.

(c) musée du quai Branly 


\title{
La danse des grands masques amazoniens
}

\author{
Chronique d'un événement
}

Franck Beuvier

1 Montpellier, le 23 juillet 2005. Station Mosson. Il est $19 \mathrm{~h} 15$ et nombre de personnes se dirigent déjà vers le domaine Bonnier de la Mosson, parc d'un magnifique château du XVIII ${ }^{e}$ siècle, pour vivre une expérience, une soirée « hors du commun ». Depuis plus d'un mois, et plus intensivement encore cette dernière semaine, la presse nationale et locale relayée par les sites d'informations culturelles rivalisent d'annonces enthousiastes vantant le caractère sensationnel de la prestation des dix-sept musiciens et danseurs wauja qui débute dans moins d'une heure :

«Pour vous ce sera une première. Pour eux aussi. En cette nouvelle année placée sous le signe du Brésil, des Indiens wauja de la région amazonienne du Xingu ont fait le voyage jusqu'à Montpellier pour présenter, lors d'une soirée exceptionnelle, leur danse traditionnelle des grands masques amazoniens. » (Le Hérault du jour, 23 juillet)

«Grande première hors du Brésil d'un rituel des Indiens wauja : la danse des grands masques amazoniens. » (Le Journal du Dimanche, 17 juillet)

«Inédit en Europe, le rituel de la cérémonie traditionnelle des Atujuwá dans laquelle masques et flûtes incarnent les esprits porteurs de guérison sera présenté par les Indiens wauja d'Amazonie. Un spectacle à ne pas manquer entre art et tradition. » (ifestival.fr)

«Une chance exceptionnelle de découvrir un pan de cette culture.» (Le Figaro, 23 juillet)

«Un événement. Un vrai, si l'on ose dire. Indiscutable. C'est certain. » (Midi Libre, 22 juillet)

« Un spectacle époustouflant!» (routard.com)

2 Notons ces deux dernières appréciations, énoncées avant même que le spectacle n'ait eu lieu ! À l'évidence le profil des Wauja fascine.

Espace vert de l'agglomération. Domaine de la Mosson. Une fois parcourue la longue allée et franchi le service de sécurité, nous pénétrons dans le parc du château. La bâtisse se dresse dans l'axe de l'allée à une centaine de mètres, et à sa droite, sur un terrain fraîchement 
débroussaillé de 7000 mètres carrés, le lieu de la cérémonie. Je décide de m'installer sur le talus qui surplombe la "scène", la propriété wauja à dire vrai : devant le rideau d'arbres en limite du domaine, la Maison des flûtes, reproduite en chaume de Camargue. Une palissade a été aménagée de part et d'autre de la maison et, sur la façade, quelques nattes de paille suspendues dessinent une large entrée, à travers laquelle on devine une forte animation. L'aire de danse, de forme plus ou moins arrondie, est délimitée par neuf piquets. La succession de pierres alignées entre les piquets en fait un espace clos.

4 La logistique est impressionnante : deux tours d'enceinte latérales, enveloppées de toiles se confondant avec le feuillage des arbres, caméra et micros fixés au sommet des piquets, et à ma gauche la régie, convertie en abri. La température est idéale, le soleil décline lentement devant nous, une légère brise souffle, et Coco Snack propose un large choix de crêpes et de boissons chaudes et froides non alcoolisées. Leur thé est parfait, quoique légèrement trop sucré.

5 Un flot quasi continu de personnes se présente maintenant. Le public, composé essentiellement d'adultes, parents et grands-parents, venus avec leurs enfants ou petitsenfants, s'installe un peu partout. Les Wauja s'apprécient en famille. Les uns se concentrent autour de l'aire de danse tandis que les autres trouvent place en périphérie. «Les gens ont tout pour pique-niquer, les couvertures et tout!", s'étonne le technicien de la régie. À ma droite, on discute du confort : «Je peux aller chercher les fauteuils dans la voiture ", propose monsieur. On se méfie des éventuelles crottes de chien et on s'émerveille du style architectural du château de la Mosson.

6 Wauja: la danse des grands masques amazoniens est la troisième manifestation de «spectacles rituels » présentée par le festival de Radio France et Montpellier, avec la collaboration de la région Languedoc-Roussillon, et le musée du quai Branly ${ }^{1}$. Elle incarne l'une des grandes ambitions de l'institution naissante: promouvoir les «spectacles vivants ${ }^{2}$ » et contribuer à la «préservation », la « revitalisation », la « valorisation » des «patrimoines immatériels ${ }^{3}$ ».

7 Cette volonté politique témoigne de la mise en œuvre au niveau de l'État français des récents engagements internationaux pris en faveur du maintien des identités culturelles et linguistiques, entérinés par la Déclaration universelle de l'UNESCO sur la diversité culturelle (Paris, 2001) et par la Convention pour la sauvegarde du patrimoine culturel immatériel (Paris, 2003). Face à la menace que font peser « les processus de mondialisation» sur l'intégrité et la production du patrimoine des "communautés autochtones ", la préoccupation est de sauvegarder leurs " pratiques, représentations, expressions, connaissances et savoir-

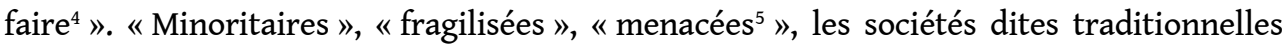
sont devenues des « perles rares » qu'il faut protéger. Leurs formes d'expression trônent désormais au rang de « joyaux » du patrimoine mondial.

8 Une présence des Indiens à la fois miraculeuse, belle et singulière, une volonté « patrimoniale » et éducative pour que ces images de culture ne tombent pas dans l'oubli mais qu'elles participent au contraire des mémoires collectives, telles seront les grandes lignes de l'intervention de René Koering ${ }^{6}$ en conférence de presse. En écho à ces déclarations, les Wauja insisteront sur le caractère préservé de leur culture et sur la nature résolument endogène de leur présentation. L'ethnographie de l'événement et l'analyse de la communication faite autour de celui-ci nous donnent à voir quelques traits contemporains de l'altérité. Une photographie d'un rapport à l'autre où se dégage une fascination pour une Amazonie mythique, un monde en voie de disparition dont les Wauja 
représentent le type idéal, un « créneau » finalement, que les intéressés investissent pour promouvoir leur culture et leur identité.

$920 \mathrm{~h} 15$. Trio de flûtes kuluta. Tandis que les premiers hululements retentissent en provenance de la Maison des flûtes, des voix s'élèvent dans le public pour demander le silence. Les mouvements, les gestes que l'on entrevoit à travers le paravent attirent irrésistiblement le regard. Les premières sonorités de flûte se font entendre puis s'arrêtent brutalement. La technique n'est pas prête. Un rapide tour d'horizon permet d'évaluer le nombre de personnes à cinq ou six cents. Le silence se fait. On attend, suspendus à ce qui va se passer.

et applaudissements et les flashs. Deux couleurs flamboyantes imprègnent cette première vision des Wauja: le jaune et le rouge, dont l'éclat est mis en valeur par le noir. Leur association domine tous les éléments de parure : la coiffe, les plumes suspendues aux oreilles, celles, plus longues, en forme de collerette dans le bas du dos, les protubérances fixées sur les brassards blancs et l'écharpe nouée à la taille. Les peintures corporelles composées de motifs géométriques visibles sur tous les endroits du corps associent le rouge et le noir. Les longues marques prolongeant les yeux, évoquant parfois la figure d'une larme, donnent au visage une expression grave, presque triste. Les trois musiciens arborent, enserrant leur poitrine, la précieuse ceinture en peau de jaguar.

11 Dans un mouvement de va-et-vient, ils entament le tour de l'espace, le dos légèrement voûté pour faciliter la marque du tempo assurée par la frappe lourde et régulière du pied droit sur le sol. En découvrant les flûtistes, leur mélodie originale, on ne peut qu'être saisi par un sentiment de respect et d'étrangeté. L'inconnu. Les repères font défaut pour appréhender ce que nous voyons et entendons. L'attention est remarquable. Les spectateurs suivent scrupuleusement leurs premiers déplacements. Chaque geste est décomposé, disséqué.

12 Le public réuni ici est tout sauf un public «populaire». Les postures, les remarques formulées, les propos échangés entre voisins témoignent davantage d'une appartenance à des catégories sociales lettrées. On serait tenté de dire que le «Tout-Montpellier » est présent ce soir. Une seconde population, principalement des jeunes adultes, regroupe les "adeptes des sociétés traditionnelles", que l'on retrouvera rassemblés dans les «coulisses" à la fin du spectacle, observant le déshabillage des Wauja et souhaitant établir un contact avec cette humanité « différente ». Quelques Brésiliens sont également présents.

13 Les flûtistes arrivent bientôt à notre hauteur. Le contraste est saisissant. La proximité induite par le passage des trois musiciens confère à l'instant quelque chose d'indéfinissable. Quel état d'esprit peut régner dans l'assistance? Quels repères le public peut-il mobiliser pour donner du sens à ce spectacle ? L'événement ayant fait l'objet d'une large couverture médiatique ${ }^{7}$, l'univers dépeint par les annonceurs nous mettra sur la voie...

14 Avec une grande précision ethnographique, le communiqué de presse du festival indique d'abord qu'une vente de masques a permis l'exhumation d'une culture. «Depuis l'expédition de Karl von den Steinen au Xingu en 1887, on n'avait plus recueilli d'informations sur ces masques et ce rituel, dont l'extinction avait même été envisagée. C'est l'acquisition d'une collection ethnographique, pour le compte du musée national d'ethnologie du Portugal, qui a permis de les "redécouvrir", confirmant l'existence d'un 
cycle scénico-rituel encore aujourd'hui d'une grande vitalité et qui fait montre d'une grande cohérence. »

Le lecteur découvre ainsi l'existence d'une authentique " petite communauté » rescapée, intacte et harmonieuse dans ses fondements. «Présents dans la forêt amazonienne depuis des centaines d'années, [les Wauja] avaient pratiquement disparu au milieu du siècle dernier. Toutefois, ces ultimes résistants surent préserver l'essentiel de leurs traditions, fondésur une esthétique de la vie sociale doublée d'un idéal de générosité et de pacifisme. » (Midi Libre)

Ce "groupe » se caractériserait par une vision du monde et de l'art étroitement imbriquée, venue du fond des âges :

«Point nodal de cette culture ancestrale : le chamanisme n'est pour eux pas qu'une simple médecine, mais un mode de connaissance du réel. Une philosophie qui affirme l'existence d'entités non humaines, les apapaatai, qui sont à la fois à l'origine des maladies et la source de guérison. Ces esprits pathogènes sont incarnés par les grands masques Atujuwá qui seront au centre du spectacle... » (Midi Libre)

«Les ornementations des masques trouvent leur origine dans les rêves; elles sont en relation directe avec la sphère de la maladie et donc d'un chamanisme à vocation thérapeutique. » (Communiqué de presse du festival)

Présenter ces masques en France requit un voyage initiatique au pays des Wauja, au cours duquel le musée du quai Branly et le festival de Radio France sont devenus les "parrains » d'un rituel collectif aux vertus curatives.

"Ces non-Wauja ont du passer par la médiation d'un "maitre" d'apapaatai, autrement dit d'une personne qui en fut jadis victime et qui, guérie, en a adopté le régime alimentaire... Ainsi fut-il fait. Et c'est donc en mars qu'eurent lieu là-bas la fabrication des masques et la distribution d'aliments et de dons aux danseurs. » (Midi Libre)

18 La cérémonie, qui a lieu chaque année au village, s'est tenue cette fois-ci avec le soutien de ces partenaires inattendus.

«Pendant presque une semaine, les masques dansent de façon intensive afin de générer la joie, sentiment indispensable à la bonne conduite des soins et in fine de la guérison » (Communiqué de presse du festival)

Peu d'informations furent données sur les modalités relatives aux accords passés. La presse mentionna seulement que les masques et les parures confectionnés à cette occasion serviraient pour la présentation programmée ce samedi.

20 À Montpellier, Aristóteles Barcelos Neto, chercheur à l'université de São Paulo et concepteur du spectacle, fournit quelques précisions sur le contexte et la nature de la prestation.

«La structure des rituels wauja permet à toute personne de les parrainer, pourvu qu'elle en ait les moyens [financiers]. » (Citation du Midi Libre)

«Il faut bien comprendre qu'ici [...] ce ne sera pas un rituel mais une performance.

[...] Parce qu'il n'y a personne à guérir. On aura la forme mais pas l'esprit de la cérémonie. » (La Gazette de Montpellier)

21 Mais le plus important est cette présence effective, présentée comme une "grâce ", un " don », quelques instants privilégiés mais éphémères:

«Je ne vais pas m'étendre sur l'histoire mais quand on me dit qu'il ne restait plus que 50 ou 60 Wauja il y a 50 ans, et qu'aujourd'hui on est arrivé à les inviter ici, pour moi, ça relève du miracle.» (René Koering, conférence de presse) « [Montpellier] est la première ville au monde (hors Brésil) à recevoir ces danseurs qu'elle ne reverra sans doute jamais plus. » (Midi Libre) 
Découvrir une survivance culturelle : voilà bien le cœur de l'événement. Ce à quoi le public est convié. Une pratique rituelle tombée dans l'oubli, une population restreinte et menacée, l'image d'une culture, dit le président du festival, qui, dans quelques décennies, aura sans doute disparu. Cette image, quelle est-elle? Celle d'une communauté éloignée géographiquement, nourrie de traditions vertueuses et partagées par tous, et imprégnée d'une cosmologie et d'une esthétique fondées sur la croyance en des entités surnaturelles. "Cœur» ou "fin fond de l'Amazonie", "culture ancestrale», "chamanisme", " esprits », « rituel » en sont les clés pour la lire. Une identité autochtone que parachève, catalyse la présentation des grands masques. Image d'un ailleurs séculaire qui constitue le premier cadre de perception des Wauja.

Pour promouvoir le spectacle, les journalistes se sont appuyés sur ces déclarations et ont repris les informations contenues dans les articles d'Aristóteles Barcelos Neto figurant dans le dossier de presse. Au fil des chroniques, si la tonalité de l'écriture dévoile l'emprise du charme engendré par la distance physique, temporelle et culturelle, elle révèle aussi de la part des auteurs une posture respectueuse à l'égard des Indiens et un souci de transcrire fidèlement leur univers à partir des sources communiquées.

De la même façon, ils n'ont laissé planer aucune ambiguïté sur la nature de la présentation. Les spectateurs n'assistent pas à l'exécution du « rituel initial » ou à « une reconstitution artificielle » dudit rituel, mais bien à « un résumé de longues séquences performatives ", « une sorte de synthèse du rituel », « son adaptation en spectacle ». Le terme le plus fréquemment employé fut celui de synthèse.

chroniqueurs ont conclu le plus souvent sur une invitation sans réserve. Les journalistes présents à la conférence de presse y ajoutèrent une pointe de vécu, manifestement séduits par les quelques propos échangés.

«Pour finir sur une note amicale et nous donner l'eau à la bouche, les deux Indiens wauja présents entonnent une chanson "dans la langue des animaux" : la chanson de l'oiseau. À la demande qui leur est faite de traduire, ils répondent, sourire aux lèvres: "C'est la langue de l'oiseau, ça ne se traduit pas." Voilà en tout cas des oiseaux rares. Si vous allez les applaudir, vous aurez l'Amazonie au bout des doigts ${ }^{8}$ .»

Une authenticité qui ne se refuse pas. Une authenticité qui mérite d'être partagée.

Danse du kuwau ('oiseau Pacurau). Les hululements annonciateurs reprennent. Regroupés au seuil du kuwakuho - maison des flûtes -, les dix-sept danseurs entonnent un chant rythmé et envoûtant. À leur tête, deux couples de masques. Les fibres finement tressées composant la cagoule se prolongent à la base du cou pour former une épaisse cape. Les masques, le bras tendu et agitant leurs maracas, s'adressent aux danseurs. Ces derniers, bras gauche levé, leur répondent. Les masques se retournent et entraînent le groupe. Ils progressent vers nous, jambes fléchies et bras ballants, dans un nuage de poussière provoqué par l'irrésistible frappe sur le sol. Ils chantent à l'unisson, intonations et gestes parfaitement synchronisés. L'intensité de leurs voix nous pénètre. L'instant est émouvant. Quelques spectateurs restés debout suivent les chants en se dodelinant, les autres regardent et écoutent attentivement.

«Ce ne sont pas du tout des voix d'hommes.»

«Leur langage, c'est curieux ? Il n'y a pas de paroles. »

« Ça doit leur esquinter la voix. »

« Ils sont bien en phase quand même : ils se répondent en même temps. » 
Cette séquence fait figure d'exception. Le caractère lancinant et monotone des mélodies n'aide pas le public à s'imprégner durablement du spectacle. Les gens se regardent, discutent, plaisantent, se déplacent éventuellement, en quête d'un nouveau point de vue.

Nous sommes installés depuis près d'une heure et l'inconfort de l'assise se fait sentir. «Ils louaient la chaise deux euros et c'était réglé ", s'emporte un monsieur. "On ne restera pas jusqu'à la fin », fait remarquer un autre à son épouse. "Moi, j’aimerais bien voir la sortie des grands masques ", insiste cette dernière. Je décide de changer de place.

Masques et danseurs terminent leur tour de chant et disparaissent dans la maison. Les applaudissements sont cette fois-ci plus nourris. "C'est formidable, on est sur place, on ne bouge pas ", se réjouit quelqu'un. Un peu plus loin, on commente la corpulence des Wauja, l'effort physique imposé par le tempo, on s'interroge enfin sur leur lieu de résidence montpelliérain.

31 Intéressés ou en quête de repères, les spectateurs consultent très régulièrement le livret de présentation. Il s'agit du dossier de presse préparé par le musée. Outre la description sommaire des différentes séquences, la majorité des articles qui le composent, rédigés par des ethnologues, nous informent sur les particularités socio-historiques des populations du Xingu, de la formation de la xinguanité au statut de la parole, en passant par le chamanisme et la portée des rituels. Le premier article est singulier, d'un intérêt particulier puisque Aristóteles Barcelos Neto y évoque les nouvelles perspectives que les Wauja envisagent désormais pour leurs cérémonies.

«La présentation de la danse des grands masques wauja au Festival de Radio France et Montpellier s'inscrit dans un contexte d'"appropriation" et de "vente" de rituels qui caractérise depuis la dernière décennie les nouvelles formes de relations entre les Blancs et les Indiens du parc indigène du Xingu. [...] L'exécution de rituels pour les non-Indiens dessine un espace dans lequel les Xinguanos peuvent manipuler les symboles de représentation politique associés à leur rapport au monde des Blancs ${ }^{9}$ .»

L'auteur poursuit en indiquant que l'expérience a déjà été menée deux fois, qu'un rituel postfunéraire a été effectué sur la demande de deux indigénistes et d'un entrepreneur brésiliens. Ces initiatives permettent aux Indiens de «capter » et d'« [apprivoiser] les signes extérieurs du pouvoir représenté par les Blancs ». Se profile ici une conjoncture qui concerne de nombreuses populations autochtones aujourd'hui.

munautés indiennes, en particulier leurs personnalités de premier plan comme les chamanes, conscientes de l'intérêt porté à leurs rituels, de la fascination qu'exercent sur les Blancs les sorties de masques, voient dans leur instrumentalisation le moyen de défendre leur identité sur la scène politique brésilienne, de promouvoir leur culture à l'extérieur et de garantir une source de revenus non négligeable.

Dans le cas montpelliérain, Aristóteles Barcelos Neto précise que le chamane devin, représentant le groupe de maitres ayant permis l'organisation de la prestation, « estimait que la vente des masques apapaatai et leur conservation dans un musée offriraient l'occasion de faire connaître la culture wauja et de financer l'achat d'équipements nécessaires au village ». Un autre objectif apparut lors de la conférence de presse, que le concepteur du spectacle et les représentants wauja formulèrent à plusieurs reprises: éditer un $\mathrm{CD}$ de musique. L'enregistrement sonore du spectacle prévu par les organisateurs offrait la possibilité - une opportunité unique - de pénétrer un marché du disque indigène porteur mais sous-alimenté ${ }^{10}$. Pour associer d'éventuels partenaires à ce 
projet, ils argumentèrent sur le caractère résolument authentique de leur culture, sur son intégrité.

«Les autres Indiens de la région du Haut-Xingu n'ont pas une culture préservée comme la culture de Xinguonne, parce qu'ils ont mélangé la leur avec d'autres, avec les Blancs ou avec d'autres cultures. [...] Notre présentation est une présentation vraiment originale. Ce n'est pas une invention pour décevoir les spectateurs [...]. Ça c'est vraiment notre culture [...]. Les chansons et la danse ont un rapport avec le rêve du chamane ${ }^{11}$.» jeu des photos et s'amusent avec les enfants. L'un d'eux se prosterne, puis court subitement, un peu au hasard, avant de s'agenouiller. D'autres l'imitent. La satisfaction du public est immédiate. "Bravo, bravo!», crient les enfants. Les spectateurs sont debout, admiratifs. Progressivement, un dialogue s'instaure entre ces nouveaux complices. Chaque pitrerie des Atujuwá se couronne par un rire ou des applaudissements, chaque rapprochement se termine en salutations. En observant cette scène, on se dit que les gens auraient souhaité être plus directement associés à la prestation. La danse des grands masques constitue la seule séquence où public et Wauja furent véritablement dans une relation d'échange, le seul moment où ils partagèrent finalement quelque chose. disparaître dans le kuwakuho. Applaudissements nourris. C'est la fin du spectacle. Les gens se dispersent maintenant, la plupart s'en vont, les autres rejoignent la Maison des flûtes ou se rendent au stand d'artisanat pour une séance commerciale durant laquelle les Wauja montrent une excellente maîtrise de l'euro!

41 Le ton employé au début de l'unique article publié au lendemain de la prestation est mitigé. 
«Pas vraiment un décor, pas vraiment non plus la place du village des Indiens wauja [...]. C'est dans cet espace intermédiaire que [s'est déroulé] le plus étrange des spectacles [...]. Étrange car il ne s'agit pas à proprement parler d'un spectacle ni de la véritable cérémonie rituelle de cette petite communauté versée dans le chamanisme. Bref, bienvenue dans un "entre-mondes" !

Un amusant détail vestimentaire des dix-sept Wauja nous le [rappela] d'ailleurs tout au long de la soirée : ils sont tous chaussés de baskets ${ }^{12}$... » stitue sans aucun doute le principal enjeu dans l'organisation de telles manifestations. Car l'engouement pour les spectacles vivants relève avant tout du désir de découvrir, d'approcher un ailleurs supposé originel, une humanité que l'on voudrait «naturelle». Un enjeu essentiel, comme en témoigne le très beau paragraphe clôturant l'article cité plus haut. Oubliant l'environnement et les baskets, le journaliste nous fait revivre au fil de son récit une soirée « enchantée ». Le " chant incantatoire » interprété par les Wauja devient pour lui « le cri de quelque oiseau de la jungle amazonienne ». Un autre monde se dévoile, « [dans lequel] le temps n'est plus la ligne droite que nous, Occidentaux, voulons croire, [...], mais un cycle reproduit à l'infini. Une dimension primale, essentielle, 
mythique, où le surnaturel est naturel. » Un fabuleux voyage qui s'achève sur cette image :

«Ce n'est plus un lopin d'Amazonie posé à Montpellier. C'est un lopin de Montpellier posé en plein cœur de l'Amazonie. Le temps d'un rêve. Sauvage et beau ${ }^{17}$.»

\section{NOTES}

1. Après Nuits du bwiti, 2002, et Musiques et danses des cités royales népalaises, 2004.

2. «Arts vivants » est l'autre appellation utilisée.

3. Catherine Monlouis-Félicité, responsable de la production des manifestations du musée du quai Branly. Propos recueillis lors de la conférence de presse, le 22 juillet 2005.

4. Ajoutons à cette liste les connaissances liées au monde et à l'environnement, et aux savoirfaire traditionnels. Convention pour la sauvegarde du patrimoine culturel immatériel. Paris, 17 octobre 2003.

5. Qualificatifs employés par la presse.

6. Président du festival de Radio France et Montpellier.

7. Une vingtaine d'articles et de chroniques ont annoncé le spectacle. La conférence de presse, les communiqués des institutions partenaires, les nombreuses interviews accordées par Aristóteles Barcelos Neto, ainsi que les deux textes de présentation qu'il a rédigés pour le dossier de presse en seront les principales sources d'inspiration.

8. Le Hérault du jour, 23 juillet 2005.

9. Wauja. La Danse des grands masques amazoniens, brochure-programme du festival de RadioFrance et Montpellier, juillet 2005.

10. L'initiative du projet revient à Aristóteles Barcelos Neto.

11. Olarou Wauja, clarinettiste et danseur. Propos recueillis lors de la conférence de presse. Traduction assurée par Aristóteles Barcelos Neto.

12. Midi Libre, 25 juillet 2005.

13. Propos recueillis lors de la conférence de presse, le 22 juillet. Emmanuel Désveaux, anthropologue et chargé de mission pour le musée du quai Branly. Il est à l'origine de la venue des Wauja à Montpellier.

14. Directrice de la recherche et de l'enseignement, musée du quai Branly.

15. Souhait formulé par Stéphane Martin, président du musée du quai Branly, dans l'introduction qu'il signe dans le dossier de presse.

16. Aristóteles Barcelos Neto, dossier de presse du musée du quai Branly.

17. Midi Libre, 25 juillet. 


\section{AUTEUR}

FRANCK BEUVIER

Ingénieur d'études au CNRS, LAHIC, franck.beuvier@culture.fr 